\title{
Identification and risk analysis of environmental management system implementation projects in municipalities
}

\author{
N. Gurets \\ Admiral Makarov National University of Shipbuilding \\ Corresponding author. E-mail: nata.gurets@gmail.com
}

Paper received 13.12.18; Accepted for publication 19.12.18.

\begin{abstract}
https://doi.org/10.31174/SEND-NT2018-186VI22-05
\end{abstract}
\begin{abstract}
Timely analysis and consideration of risks in project management of the implementation of an environmental management system in municipalities increases the efficiency of project implementation. The risks of such projects are identified in the article. It has been demonstrated that risk events complicate the project management process. A qualitative and quantitative analyzes of the impact of risks on the implementation projects of the environmental management system in municipalities have been carried out. The groups of risks that have the most negative impact on the implementationof projects are defined and methods of their reduction are offered.
\end{abstract}

Keywords: risk, risk management, environmental management system, project management, municipality.

Introduction. One of the most characteristic features of the development of modern society is the rapid growth of cities, the continuous rate of increase in the number of their inhabitants and the transformation of rural areas into urban ones. This process, in turn, leads to environmental degradation on the territory of municipalities due to an increase in production capacity of new industries and the aggravation of their impact on nature; the increase in the volume of hazardous waste generation and the number of vehicles, which necessitates the implementation of the environmental management system (EMS) in municipalities.

The implementation of environmental management in municipalities is being carried out through the development and implementation of EMS projects. As a result of the implementation of such projects, the level of pollution by emissions and discharges of harmful substances is being reduced; there is an economy of energy and natural resources, and, accordingly, the funds of the organization; the state of the environment is improving; the "green" image of the organization is increasing; the relationships between different groups of local residents are improving. During the implementation of the EMS projects, there is a reorganization of the current structure of the local government, the redistribution of responsibility between different departments, which, in turn, can cause the occurrence of risky events of various kinds.

Overview of related publications. Modern project management methodology considers the risk in projects from the point of view of different approaches and classifications that are closely related to the peculiarities of the projects themselves. So, in the works of Druzhynin E. A. [4], a methodology for a risk-oriented approach to the management of project resources and technology development programs has been developed. Rach V.A. [10] considered risk in the development processes in the modern economy as a component of the danger-risk-crisis triad. Danchenko O.B. [2] studied the process of integrating well-known modern approaches to risk management into one process that would take into account the peculiarities of risk management in various methodologies. Gogunskyi V.D. [5] analyzed the risk management process in labor safety projects. McNeil A. J. studied the issues of risk management analysis, noting that its goal is to identify and estimate potential threats, and then choosing the appropriate method to reduce or eliminate hazards
[14]. In the works $[1,11]$, the authors substantiated the need for continuous analysis and control of risks in order to prevent and reduce their impact on the implementation of scientific projects and portfolios of projects of scienceintensive enterprises. The study of issues of identification and risk assessment of investment projects is devoted to the works $[6,7]$.

The analysis of the literature allows us to determine the general approaches to the interpretation of the concept of risk. Thus, according to the approach proposed by Nepomniashchii E. G. [9], the risk is the possibility of a certain danger, which negatively affects the results of the organization activities. Golubev D. I. [6] characterizes the risk as uncertainty related to the possibility of adverse situations and consequences occurring during the project implementation. Some authors interpret the risk as a component of a certain type of activity, which depends on factors of the external and internal environment, which can result in non-receipt of planned results, as well as their successful implementation.

EMS implementation projects in municipalities belong to organizational type projects with elements of communication projects. Regarding the risks of implementing organizational projects, Kostsyk R. S. [8] notes that they represent the probability of occurrence of a certain event, which can carry both negative and positive consequences, and is characterized by uncertainty, ambivalence and alternativeness of possible options when making organizational changes. According to N. Drahomyretska [4], the essence of the risk for communication projects is the possibility of deviation from the intended goal; in the absence of confidence in achieving the goal; expectation of danger, failure as a result of choosing an alternative and its implementation.

The purpose of the article is to identify risks specific to the EMS implementation projects, their quantitative and qualitative assessment, which will clearly determine the place of each risk in the overall system of risk factors and create prerequisites for the further effective application of appropriate risk management methods and techniques.

Materials and methods. For the first time, the project of implementation for environmental management system at the Mykolaiv City Executive Committee was implemented in 2000 (as part of the TACIS program for the implementation of environmental management stand- 
ards).During the project implementation, the EMS was implemented in three divisions of the Mykolayiv City Executive Committee.Over the next ten years, EMS was gradually being introduced into the activities of other units. In addition, in accordance with the requirements of the environmental management standard, the process of continuous improvement of the system is ensured by annual internal audit. In the course of the study, the documentation of the implementation of the above-mentioned projects, the specialized documentation of the EMS were analyzed, and interviews were conducted with project managers and employees of the units in which the EMS operates. Data was also used on the results of the EMS implementation in the activities of the city government, namely, environmental indicators of the state of atmospheric air and surface water, the consumption of certain natural resources, data on the number of conflicts arising in land allotments for construction in green areas.

Results and its discussion. The EMS implementation project in the organization according to 14001:2015 [15] includes the development of environmental policy; planning of activities in accordance with the adopted policy and goals; implementing and functioning of the EMS; conducting inspections and corrective actions; conducting a management review to ensure continuous improvement of the EMS.

Environmental policy is the development and approval of environmental goals and objectives. When developing an environmental policy they based on the interests of stakeholders. They need to be clearly formulated and prioritized, taking into account all interests. This process is cyclical and it leads to the development of EMS. The planning process includes the following elements: the determination of environmental aspects; determination of relevant legal regulations and requirements to be met; determination of internal performance criteria; the establishment of target and planned environmental indicators, as well as the implementation of programs for their achievement. At the implementation and operation stage, the organization and implementation of the planned activities involving all personnel are carried out. The next stage should contribute to planning, controling, monitoring, corrective actions, analysis and auditing in order to ensure that the EMS is consistent with its ongoing policy and support at the appropriate level. Conducting inspections and corrections allow the EMS to be able to change under the influence of circumstances. At the management review stage, the top management of the organization should analyze the EMS at intervals set by it in order to ensure the continuous improvement of the EMS, its adequacy and effectiveness.

In the course of the project implementation, the search is carried out for the correspondence between the key elements of the organization, such as structure, personnel, tasks, a system of solutions and incentives, culture and its strategy in achieving success, therefore, according to the nature and scope of work, such a project is of an organizational type. Such a project, especially for structurally complex organizations, is being developed in two stages: a draft design considers alternative reorganization options and a working draft, which is being developed in three stages. At the first stage, a new general structural scheme of the organization is formed, at the second - a new com- position of the main units and relations between them is developed, at the third stage, the organizational structure is regulated.

Traditionally, risk management is aimed at managing known and unknown risk scenarios [11]. To avoid project failure, the risk management methodology involves the use of the following processes [13]: identifying risks, analyzing and assessing risks, responding to the occurrence of a risk event, applying risk reduction techniques, documenting risk management processes for further applying this knowledge. Risk management related with the implementation of the EMS implementation projects is a rather complicated process, especially given the very high degree of uncertainty. However, risk analysis of such projects and their systematization can already provide tools for risk management. There are two types of risk analysis that mutually complement each other: qualitative and quantitative ones. Qualitative risk analysis aims to identify factors, areas and types of risk. Quantitative analysis makes it possible to numerically determine the size of individual risks and the risk of the project as a whole. [2].

We will conduct a preliminary qualitative analysis of the risks of influence on the process of managing an EMS implementation project in a municipality. Based on the specifics of implementing the EMS implementation projects and the specifics of their management, the following risk groups can be distinguished: management risks, risks related to external stakeholders, economic risks, personnel risks, political, internal project and other risks.

Management risks are related to the project strategy mismatch, mismatch of the project team, deviations in information systems and internal control, management errors, insufficiency of financial resources, innovation, and problems with suppliers. Risks related to external stakeholders include risks caused by social tensions, lack of communication between stakeholders, the uncertainty of their goals, interests and behavior, the disinterest of the local community, the loss of local government reputation, and the risks of the contractor and the supplier. Economic risks are related to inflation, capital investment, the possibility of yield curve risk, crediting, direct financial losses, taxes and economic instability.

Personnel risks include the risk of conflict of interest, the risk of incompetence, the risk of lack of experience, the leadership risk, the risk of resistance to organizational changes, and the risk of loss of management support. Political risks are related to with the possibility of deterioration of the political situation, unfavorable social and political changes, unpredictable legislative changes, the occurrence of local conflicts and changes in the management of the local government. Internal project risks occur in the event of choosing the wrong project implementation technology, budget mismatch, disrupting of work plans, revealing of incompleteness or inaccuracy of project documentation, errors in project documentation, incomplete or inaccurate information about the financial status of project participants, changes the priorities in the enterprise development. Other risks include legal, environmental, information and force majeure risks.

The identified the risks of the EMS implementation project in municipalities are presented in the form of a cause-effect Ishikawa diagram [12] (Fig. 1.) 


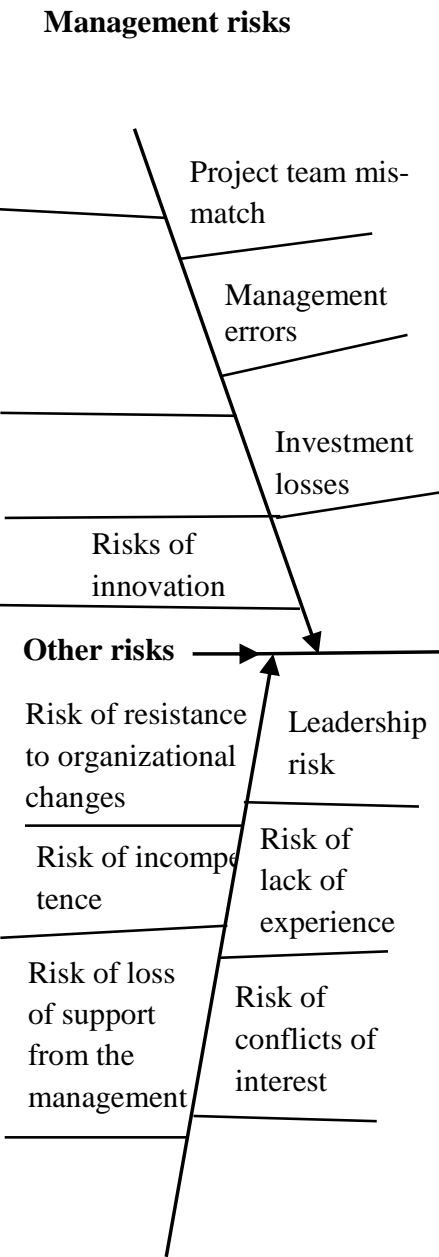

Personnel risks
Risks related to external stakeholders

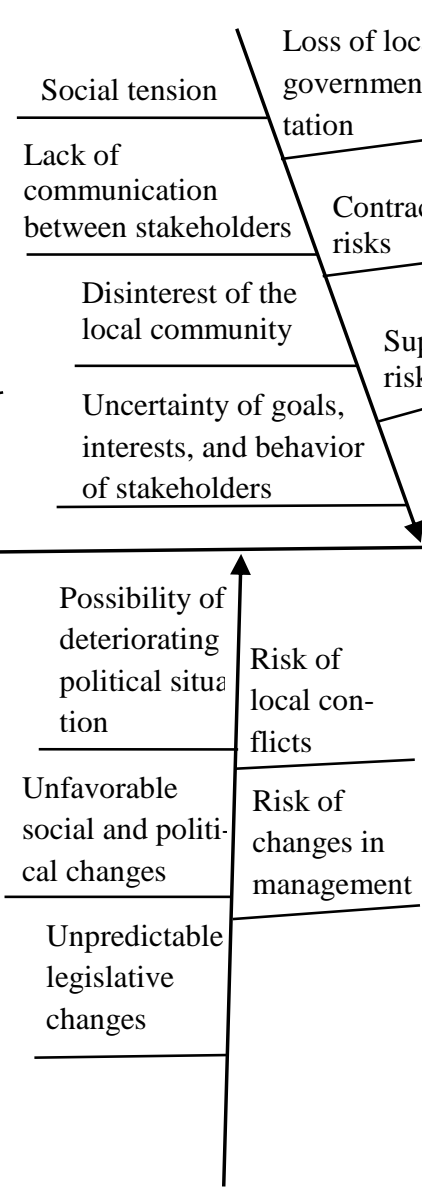

Political risks

Economic risks

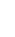

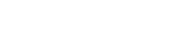 \\ cor}

\author{
Ecomomic risks
}

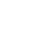

(1) 
Table 1. - Matrix of risk identification in the implementation of EMS implementation projects in accordance with the project implementation stage.

\begin{tabular}{|c|c|c|c|c|c|c|}
\hline \multirow[b]{2}{*}{ Risk name } & \multirow[b]{2}{*}{ Risk rating } & \multicolumn{5}{|c|}{$\begin{array}{c}\text { Stages of implementation of EMS implementation } \\
\text { projects in organizations }\end{array}$} \\
\hline & & 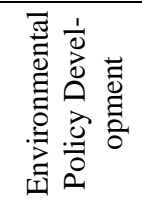 & 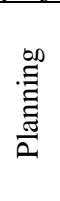 & 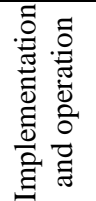 & 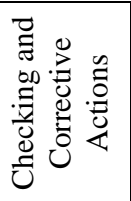 & 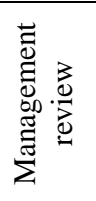 \\
\hline 1 & 2 & 3 & 4 & 5 & 6 & 7 \\
\hline \multicolumn{7}{|c|}{ Management risks } \\
\hline 1. Strategy mismatch & High & + & & & & \\
\hline 2. Project team mismatch & High & & + & + & + & + \\
\hline 3. Deviation in information systems and internal control & High & & & + & + & + \\
\hline 5. Management errors & High & + & & + & + & + \\
\hline 6. Insufficiency of financial resources & Medium & & + & + & & \\
\hline 7. Risks of innovation & High & & + & + & & \\
\hline 8. Investment losses & High & & + & + & & \\
\hline \multicolumn{7}{|c|}{ Risks related to external stakeholders } \\
\hline 9. Social tension & High & + & + & & + & + \\
\hline 10. Lack of communication between stakeholders & High & + & + & & + & + \\
\hline 11. Disinterest of the local community & High & + & + & & + & + \\
\hline $\begin{array}{l}\text { 12. Uncertainty of goals, interests, and behavior of stake- } \\
\text { holders }\end{array}$ & High & + & + & & + & + \\
\hline 13. Loss of local government reputation & High & + & + & & + & + \\
\hline 14. Contractor Risks & Medium & & + & + & & \\
\hline 15.Supplier risks & Medium & & + & + & & \\
\hline \multicolumn{7}{|c|}{ Economic risks } \\
\hline 16. Inflation risk & Medium & + & + & + & & \\
\hline 17. Capital Risk & Medium & + & + & + & & \\
\hline 18. Yield curve risk & Low & & + & + & & \\
\hline 19. Credit risk & Medium & & + & + & & \\
\hline 20. Risk of direct financial losses & Medium & & + & + & & \\
\hline 21. Tax risk & Low & & & & & \\
\hline 22.Risk of an economic instability & Medium & & + & + & & \\
\hline \multicolumn{7}{|c|}{ Personnel risks } \\
\hline 23. Risk of conflicts of interest & High & + & + & + & + & + \\
\hline 24. Risk of incompetence & High & + & + & + & + & + \\
\hline 25. Risk of lack of experience & High & + & + & + & + & + \\
\hline 26. Leadership risk & High & + & + & + & + & + \\
\hline 27. Risk of resistance to organizational changes & High & + & + & + & + & + \\
\hline 28. Risk of loss of support from the management & High & + & + & + & + & + \\
\hline \multicolumn{7}{|c|}{ Political risks } \\
\hline 29. Possibility of deteriorating political situation & Medium & + & + & + & + & + \\
\hline 30. Unfavorable social and political changes & High & + & + & + & + & + \\
\hline 31. Risk of changes in management & High & + & + & + & + & + \\
\hline 32. Unpredictable legislative changes & High & + & + & + & + & + \\
\hline 33. Risk of local conflicts & Medium & + & + & + & + & + \\
\hline \multicolumn{7}{|c|}{ Internal project risks } \\
\hline 34. Risk of budget mismatch & High & & + & + & & \\
\hline $\begin{array}{l}\text { 35. Risk of choosing the wrong project implementation } \\
\text { technology }\end{array}$ & High & + & + & + & + & + \\
\hline 36. Disrupting work plans & High & & & + & + & + \\
\hline $\begin{array}{l}\text { 37. Incompleteness or inaccuracy of project documenta- } \\
\text { tion }\end{array}$ & High & & & + & + & + \\
\hline 38. Errors in the project documentation & High & & & + & + & + \\
\hline 39. Production and technical risk & Low & & & + & + & + \\
\hline $\begin{array}{l}\text { 40. Risk of changing priorities in the enterprise develop- } \\
\text { ment }\end{array}$ & Medium & + & + & + & + & + \\
\hline $\begin{array}{l}\text { 41.Incomplete or inaccurate information about the finan- } \\
\text { cial status of project participants }\end{array}$ & High & + & + & + & & \\
\hline \multicolumn{7}{|c|}{ Other risks } \\
\hline 42.Legal risk & Medium & + & + & + & + & + \\
\hline 43. Environmental risk & Medium & & & + & + & + \\
\hline 44. Information risk & High & + & + & + & + & + \\
\hline 45. Force majeure risk & Medium & & & + & & \\
\hline
\end{tabular}


Table 2. - Matrix of probabilities of occurrence of risks for EMS implementation projects

\begin{tabular}{|c|c|c|c|c|c|}
\hline $\begin{array}{c}\text { Average probability } \\
\text { of occurrence } \\
(0,0 \div 1,0)\end{array}$ & 0,1 & 0,3 & 0,5 & 0,7 & 0,9 \\
\hline $0,8 \div 1,0$ & & & & & \\
\hline $0,6 \div 0,8$ & & & $12,21,28,36$ & $1,2,30,31,34$ & \\
\hline $0,4 \div 0,6$ & & $13,14,33,39$ & $25,35,40,42$ & $9,23,24,43$ & $10,11,22,26$ \\
\hline $0,2 \div 0,4$ & $6,7,15,18,44$ & $8,20,32$ & $29,31,27,37$ & \\
\hline $0,0 \div 0,2$ & $17,20,38$ & $5,16,19,41$ & $3,4,29$ & & \\
\hline \multicolumn{5}{|c|}{$\begin{array}{c}\text { Where: } \\
\text { - high risk zone } \\
\text { - moderate risk zone } \\
\text { - low risk zone }\end{array}$} \\
\hline
\end{tabular}

For EMS implementation projects that are part of organizational projects, the most effective risk reduction methods are risk distribution between project participants, fund reservation or self-insurance, and improving management efficiency. The risk distribution is being carried out in the course of preparation of the project plan and contract documents. For the quantitative distribution of risks in projects, a model based on the "decision tree" can be used. At the same time, each participant performs the planned amount of work and bears the corresponding share of risk in case of non-fulfillment of the project.

Conclusions. The results of the study showed that risk events complicate the project management process, and therefore, risk management tools and their implications are needed. The identified risks of EMS implementation projects can be divided into six groups. The qualitative and quantitative analyzes of the impact of risks on EMS implementation projects have shown that such projects are characterized by a high probability of occurrence of such groups of risks as management risks; risks related to external stakeholders; personnel risks; political and information risks. The proposed risk management measures can significantly reduce the risks of EMS implementation projects.

\section{REFERENCES}

1. Danchenko, O. B.; Bedrii, D. I.; Semko, I. B. Identification of personnel risks of scientific projects // Project Management and Production Development, 2017. No. 4 (64). P. 18-24.

2. Danchenko, O. B. Review of modern risk management methodologies in projects // Project Management and Production Development, 2014. No. 1 (49). P. 16-25.

3. Dragomiretska, N. Composition of risk management in communication projects // Education of the Region: Political Science, Psychology, Communication, 2009. No. 1 P. 139-144.

4. Druzhynin, E. A. Mathematical support of information technology for the integration of processes when planning projects, taking into account the influence of risk factors // Project Management and Production Development, 2014, No. 2 (50). P. 42-48.

5. Gogunskyi, V. D.; Chergnega, Yu.S. Risk Management in Occupational Safety Projects as a Method for Elimination of Harmful and Dangerous Working Conditions // East European Journal of Advanced Technologies, 2013. No. 1/10 (61). P. 83-85.

6. Golubev, D. I. Features of risks and uncertainties in assessing the effectiveness of investment project management // Bulletin of the Zaporizhzhya National University, 2015. No. 2 (26). P. 17-26.

7. Kadyrbaev, I. A. Theoretical issues of investment risk research, main features and classification // MIR (Modernization. Innovations. Development), 2016. Vol. 7. No. 3. P. 181188.
8. Kostsyk, R. S. Risks of the implementation of organizational changes: essence, classification and identification // Bulletin of the Lviv Polytechnic National University, 2010. No. 682: Management and Entrepreneurship in Ukraine: Stages of Development and Developmental Issues. - P. 65-71.

9. Nepomnyashchii, E.G. Investment design, 2003. Taganrog, Russia. 262 p.

10. Rach, V. A. "Danger / risk / crisis" as a triad essence of development processes in the modern economy// Project management and production development, 2013. No. 1. - P. 155-160.

11. Savina, O. Yu.; Kharuta, V. S. Risk management for project portfolios of science-based enterprises // Bulletin of the National Transport University, 2018. - Is. 1 (40). P. 285-298.

12. Logunova O. E. Application of the causal of Ishikawa diagram in reputation management // Scientific Research, 2015. № 1 p. 54-56.

13. A Guide to the Project Management Body of Knowledge(PMBOK), Sixth edition, Project Management Institute, Pennsylvania, USA, 2017, 756 p.

14. McNeil A. J.; Frey R.; Embrechts P., Risk Management, Concepts Techniques Tools, Princeton University Press, New Jersey, 2005.

15. ISO 14001:2015 Environmental management systems Requirements with guidance for use, Third edition, 2015, 35 p. 